\title{
RETRACTION \\ Spry2 regulates signalling dynamics and terminal bud branching behaviour during lung development - RETRACTION
}

YINGYING ZHAO AND TIMOTHY P. O’BRIEN

The article cited above (Zhao and O'Brien, 2015) was submitted for publication in the journal Genetics Research on the assumption that all co-authors had agreed to the submission. However, Dr O'Brien had not consented to the submission and subsequent publication of this manuscript.

The Publisher has agreed to retract this manuscript.

\section{Reference}

Yingying Zhao and Timothy P. O’brien (2015). Spry2 regulates signalling dynamics and terminal bud branching behaviour during lung development. Genetics Research, 97, e5 doi:10.1017/S0016672315000026. 